Çukurova Üniversitesi Mühendislik Mimarlık Fakültesi Dergisi, 32(1), ss. 155-163, Mart 2017

Çukurova University Journal of the Faculty of Engineering and Architecture, 32(1), pp.155-163, March 2017

\title{
Kitosan Destekli Au Nanopartiküller ile Modifiye Edilmiş Alüminyum Elektrotta Hidrojen Gazı Üretimi
}

\author{
Didem BALUN KAYAN*1, Merve ÍLHAN ${ }^{1}$, Derya KOÇAK ${ }^{1}$ \\ ${ }^{1}$ Aksaray Üniversitesi, Fen Edebiyat Fakültesi, Kimya Bölümü, Aksaray \\ Geliş tarihi: 09.01.2017_ Kabul tarihi: 14.03 .2017
}

\section{$\ddot{\mathbf{O z}}$}

Günümüzün en büyük problemlerinden biri, enerji gereksiniminin karşılanmasında çok büyük oranda fosil yakıtların kullanılmasıdır. Artan enerji ihtiyacının fosil yakıtlardan sağlanması, çevresel problemlere ve enerji maliyetinin artmasına neden olmaktadır. Bu problemlerin çözümü ancak sürdürülebilir enerji kaynakları kullanımıyla gerçekleştirilebilecektir. Bu yüzden bol miktarda bulunan hidrojen, temiz ve ideal bir yakıt olarak geleceğin enerji kaynağı olarak düşünülmektedir. Hidrojen gazı üretiminin en basit yolu suyun elektrolizidir. Suyun elektrolizi ile hidrojen üretiminde karşılaşılan en büyük problem, elektrokimyasal sistemde oluşan aşırı gerilim nedeniyle maliyet artışıdır. Bu çalışmada suyun elektrolizi ile hidrojen elde etmek amaciyla ucuz bir materyal olarak seçilen alüminyum elektrodun yüzeyi, önce polianilin (PAni)-Kitosan kompozit yapısıyla modifiye edilmiş, daha sonra elde edilen bu kompozit yapı üzerine hidrojen oluşumunda yüksek katalitik aktivite gösteren altın $(\mathrm{Au})$ nanopartiküller ayrıştırılmıştır. Elde edilen tüm yapıların yüzey özellikleri incelenmiş ve elektrokimyasal hidrojen üretimindeki katalitik aktiviteleri çeşitli elektrokimyasal yöntemler kullanılarak karşılaştırılmıştır.

Anahtar Kelimeler: Hidrojen enerjisi, Elektrokataliz, İletken polimer, Kitosan, Au nanopartikül

\section{Hydrogen Gas Production on Aluminium Electrode Modified by Chitosan Supported with Au Nanoparticles}

\begin{abstract}
One of the major problems of today's world is in its heavy dependency on fossil fuels for energy requirements. The increase in energy requirements causes environmental problems and leads to an increase in energy costs. It has already been obvious that the solution to these problems is to use of sustainable energy resources. Since hydrogen, the most abundant element is the cleanest and ideal fuel, has been considered as the fuel of the future. The simplest way of hydrogen production is the electrolysis of water. The major problem in the electrolysis of water for the hydrogen evolution is the increase in costs due to overvoltage of the electrochemical system. In this study, first the surface of the aluminium electrode as a cheap material, coated with polyanilin (PAni)-Chitosan composite film, then the gold (Au) nanoparticles electrodeposited on this composite surface which show high catalytic activity toward hydrogen production. The surface properties of the all obtained structures are investigated and the catalytic activities of the structures are compared with various electrochemical techniques for the electrocatalytic hydrogen production.
\end{abstract}

Keywords: Hydrogen energy, Electrocatalysis, Conducting polymer, Chitosan, Au nanoparticle

*Sorumlu yazar (Corresponding author): Didem BALUN KAYAN, didembalun@aksaray.edu.tr 


\section{GíRiș}

Alternatif enerji kaynakları arayışı çok uzun süredir bilim adamlarının gündeminde yer alan ve tüm insanlığı ilgilendiren önemli bir araştırma konusudur. Özellikle çevreye zarar vermemesi, yenilenebilir ve düşük maliyetli olması alternatif bir enerji kaynağının taşıması gereken en önemli özelliklerdir. Bu anlamda alternatif enerji kaynağı olarak hidrojen enerjisi, verimli ve temiz bir yakıt olduğundan ayrıca fosil yakıtların sebep olduğu çevresel sorunlara yol açmadığından, bir enerji sisteminin sahip olması gereken hemen hemen tüm özellikleri taşımaktadır. Hidrojen doğal bir yakıt olmayıp, diğer enerji kaynaklarından yararlanılarak üretilebilen sentetik bir yakıttır. Dünyada bol miktarda bulunan hidrojen doğada serbest halde değil, bileşikleri halinde bulunmaktadır. En iyi bilinen bileşiği sudur ve en basit üretim yöntemi suyun elektrolizidir. Ancak suyun elektroliziyle hidrojen üretiminde, elektrokimyasal sistemde meydana gelen aşırı gerilim, yöntemin maliyetini arttıran bir dezavantaj durumundadır. Sudan hidrojen üretimi ile ilgili ilk çalışmalar Fujishima ve Honda [1] tarafindan $\mathrm{TiO}_{2}$ elektrot kullanılarak fotokatalitik olarak gerçekleştirilmiştir. Daha sonra farklı elektrokatalizörlerde hidrojenin daha az enerjiyle ekonomik olarak sudan üretimi üzerine çalışmalar yoğunlaşmış, özellikle son yıllarda verimliliği arttırabilmek, kararlı, ucuz ve kullanılabilir elektrot materyalleri geliştirebilmek amacıyla birçok çalışma yapılmıştır [2-7].

Günümüzde elektrokatalitik hidrojen üretiminde en aktif katalizörlerin Pt grubu metallerinin olduğu ama bu metallerin yüksek maliyetlerinden dolayı katı metal elektrot olarak kullanımlarının sinırlı kaldığı bilinmektedir [8-10]. Dolayısıyla hidrojen oluşumu reaksiyonu (HER) için daha düşük maliyetli yeni elektrotların geliştirilmesi gerekmektedir. Literatürde farklı metal, metal oksitler ve farklı iletken polimerle modifiye edilmiş elektrotlarda elektrokatalitik hidrojen oluşumu reaksiyonunun incelendiği çalışmalar giderek artmaktadir.

Polianilin, elektrokimyasal uygulamalarda yaygın olarak çalışılan iletken polimerlerdendir. Ancak endüstriyel uygulamalarda işlenebilirliğinin ve mekaniksel özelliğinin zayıf olması kullanım alanını sinırlamaktadır. $\mathrm{Bu}$ yüzden iletken polimerlerin farklı materyallerle kompozitlerinin hazırlandığı çok sayıda çalışmalar gerçekleştirilmiştir [11-14]. İletken polimerlerin soy metallerle kompozitleri teknolojik uygulamalar açısından oldukça önemlidir. Özellikle mikro ve nano boyutta metal partiküller içeren iletken polimer kompozitleri mikro elektronikte ve sensörlerde geniş kullanım alanı bulmaktadırlar [15-17].

Doğal bir biyopolimer olan kitosan, son yıllarda metaller için destek materyali olarak kullanılmaya başlanmıştır. Yapısındaki $-\mathrm{OH}$ ve $-\mathrm{NH}_{2}$ gibi aktif gruplar nedeniyle metallerle etkileşimi yüksek olan kitosanın soy metallerle ve geçiş metalleriyle kompozitleri elde edilmektedir [18-20].

Diğer taraftan, alüminyum ve alaşımları, sahip oldukları mekaniksel, elektriksel ve termal özelliklerinin yanında hafifliklerinden dolayı, taşımacılık, inşaat, paketleme ve elektronik gibi birçok alanda kullanım alanı bulmaktadırlar. Tamamen geri dönüşüme katılabilmesinden dolayı alüminyuma "yaşayan metal" denilmekte, maliyeti, uygulanabilirliği, çevre güvenliği ve hidrojen üretiminde kullanılabilirliği açısından alüminyum, günümüzün sürdürülebilir enerji teması açısından önemli bir metal sayllabilmektedir [21-22]. Alüminyumun iletken polimer ile kaplanması, yüzeyinde oluşan ince fakat yüksek kararlılığa ve elektriksel dirence sahip oksit $\left(\mathrm{Al}_{2} \mathrm{O}_{3}\right)$ filmden dolayı oldukça zordur. Bu koruyucu film, yüzeyde polimer oluşumu sirasındaki elektron transferini engellemekte ve polimerizasyon potansiyelini daha pozitif değerlere kaydırmaktadır. $\mathrm{Bu}$ nedenle bu konuda yapılan çalışma sayısı çok fazla değildir.

Bu çalışma kapsamında alternatif, yenilenebilir ve temiz hidrojen enerjisinin elektrokatalitik olarak sudan elde edilmesi tasarlanmıştır. Düşük maliyetli alüminyum elektrodun, doğal bir biyopolimer olan kitosan varlığında anilin ile eş zamanlı elektropolimerizasyonu sağlanmış, elde edilen kompozit yapı üzerine, elektrokatalitik aktivitesi yüksek olan altın metalinin nano boyutta biriktirilmesiyle nispeten düşük maliyetli bir 
elektrokatalizör geliştirilmiştir. Geliştirilen bu elektrokatalizörün hidrojen üretimindeki katalitik etkinliği elektrokimyasal yöntemlerle incelenmiştir.

\section{MATERYAL ve METOT}

Çalışma elektrodu olarak \%99,99 saflıktaki $3 \mathrm{~mm}$ çaplı alüminyum elektrot, uç kısmı açıkta kalacak şekilde polyester ile soğuk kaplama yapılarak hazırlanmıştır. Hazırlanan alüminyum elektrot, kalından inceye doğru zımpara kağıtları ile zımparalandiktan sonra $5 \mathrm{dk}$ etil alkol içerisinde, daha sonra $5 \mathrm{dk}$ saf su içerisinde bekletilerek yüzeydeki safsızlıklar giderilmiştir. Böylece alüminyum elektrot, polimerizasyon için kullanıma hazır hale getirilmiştir. Elektropolimerizasyon için, $0,174 \mathrm{M}$ anilin ihtiva eden $0,3 \mathrm{M}$ okzalik asit çözeltisine 0,01 g kitosan eklenmiş (toplam $5 \mathrm{~mL}$ çözelti), sonra bu çözeltiye $5 \mathrm{~mL} 1,5 \mathrm{M} \mathrm{p}$ toluensülfonik asit çözeltisi eklenmiştir (toplam 10 $\mathrm{mL}$ ). Elde edilen elektrolit çözeltisi iyice karıştırılarak homojen hale getirilmiş, her deney öncesinde taze olarak hazırlanmıştır. Hazırlanan alüminyum elektrot, anilin-kitosan çözeltisine daldırılarak elektropolimerizasyon işlemi dönüşümlü voltametri yöntemiyle gerçekleştirilmiştir. Tüm ölçümlerde karşı elektrot olarak Pt tel, referans elektrot olarak $\mathrm{Ag} / \mathrm{AgCl} / \mathrm{Cl}^{-}$ elektrot kullanılmış, ölçümler standart cam hücrede gerçekleştirilmiştir. $-0,2 \mathrm{~V}$ ile $+1,25 \mathrm{~V}$ potansiyel aralığında, $10 \mathrm{mV} / \mathrm{s}$ tarama hızıyla dönüşümlü voltametri tekniği kullanılarak elektropolimerizasyon gerçekleştirilmiştir. 25 döngü sonucunda alüminyum elektrodun yüzeyi homojen olarak kaplanmış ve film kalınlığı, son döngüde elde edilen ilk anodik pik için geçen yük miktarından $\left(145 \quad \mathrm{mC} . \mathrm{cm}^{-2}\right) \quad 2,2 \mu \mathrm{m}$ olarak hesaplanmıştır.

Elde edilen kompozit yapıdan monomer ve dimer gibi safsızlıkların uzaklaştırılması için kompozit film ile kaplanan elektrot saf su ile yikandiktan sonra $0,5 \mathrm{M} \mathrm{H}_{2} \mathrm{SO}_{4}$ çözeltisinde $5 \mathrm{dk}$ bekletilip karakterizasyon işlemleri ve elektrokimyasal ölçümler gerçekleştirilmiştir.

Alüminyum elektrodun PAni-Kitosan kompozit yapisıyla modifiye edilmesinden sonra elektrokatalitik aktifliği yüksek $\mathrm{Au}$ metalinin kompozit yapı üzerine elektrodepozisyonu gerçekleştirilmiştir. Altının kompozit yüzeye elektrodepozisyonu, $1 \mathrm{mM} \mathrm{HAuCl}_{4}$ (kloroaurik asit) içeren $0,5 \mathrm{M} \mathrm{H}_{2} \mathrm{SO}_{4}$ elektrolit ortamında, $-0,2 \mathrm{~V}$ ile $+1,3 \mathrm{~V}$ potansiyel aralığında $50 \mathrm{mV} / \mathrm{s}$ tarama hızıyla dönüşümlü voltametri yöntemiyle gerçekleştirilmiştir. Kompozit film üzerine biriken Au miktarı, $\mathrm{m}_{\mathrm{Au}}=\mathrm{Q}_{\mathrm{Au}} \cdot \mathrm{M}_{\mathrm{Au}} / \mathrm{nF}$ eşitliğine göre $80 \mu \mathrm{g}$ olarak hesaplanmış olup, $\mathrm{Q}_{\mathrm{Au}} ;$ altının elektrodepozisyonu sirasında geçen yükü, $\mathrm{M}_{\mathrm{Au}}=196,9 \mathrm{~g} / \mathrm{mol}$; altının atomik kütlesini, $\mathrm{n}=3$; transfer edilen elektron sayısını ve $\mathrm{F}=96485 \mathrm{C} / \mathrm{mol}$ olarak Faraday sabitini göstermektedir.

Elektrokimyasal tüm işlemler, Gamry (Interface 1000) marka Elektrokimyasal Çalışma Ünitesi kullanılarak gerçekleştirilmiştir. Elde edilen kompozit filmlerin yüzey özellikleri, FEI Quanta 250 FEG marka taramalı elektron mikroskobu (SEM) ile analiz edilmiş, kimyasal kompozisyonları SEM cihazına integre edilmiş enerji dağılım spektrometresi (EDAX) ile belirlenmiştir. Ayrıca kompozit filmlerin yapı analizleri, Perkin Elmer Spectrum 100 FTIR marka, Fourier Transform Infrared (FT-IR) spektroskopisi cihazıyla gerçekleştirilmiştir.

\section{BULGULAR ve TARTIŞMA}

\subsection{Yüzey Özellikleri}

Kompozit filmlerle kaplanan alüminyum elektrodun ilk olarak yüzey morfolojileri incelenmiş, yüzey özelliklerini incelemek için taramalı elektron mikroskobu (SEM) kullanılmıştır (Şekil 1). Şekil 1a'da polianilin iletken polimerinin tipik saçaklı yapısı görülmektedir. Polianilinin yapısına kitosanın katılmasıyla elde edilen filmde, gözenek çapının küçüldüğü, daha kompakt bir yüzey elde edildiği dolayısıyla kitosanın yapıya katılmasıyla film özelliğini iyileştirdiği görülmüştür (b). Polianilin-Kitosan kompozit yapısının üzerine altının elektrodepozisyonu sonucunda elde edilen film yüzeyinde altın partiküllerinin homojen bir şekilde dağıldığ partikül çaplarının 65-95 nm aralığında olduğu görülmektedir (d). 

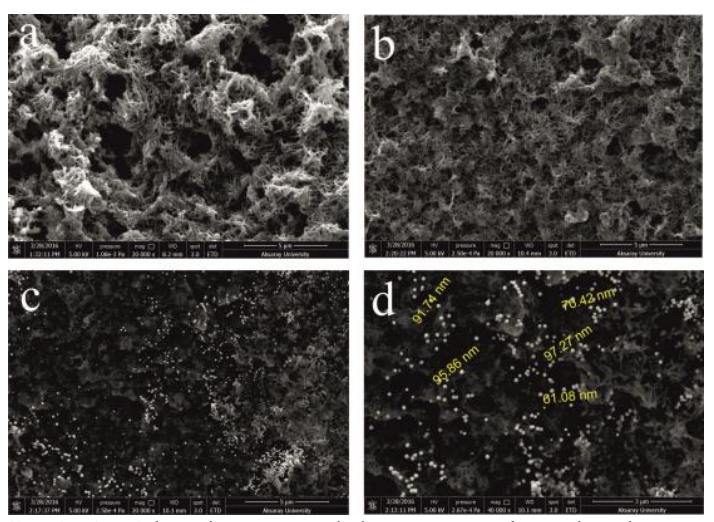

Şekil 1. Alüminyum elektrot üzerine kaplanmıs a)PAni filminin, b) PAni-Kitosan, c)PAni-Kitosan/Au ve d) daha yüksek büyütme oranında çekilmiş PAniKitosan/Au kompozit filmlerinin SEM görüntüleri

Görüntüleri alınan PAni-Kitosan/Au kompozit yapısının ayrıca yüzey kompozisyonu enerji dağılım spektroskopisi (EDS) ile aydınlatılmıştır (Şekil 2).

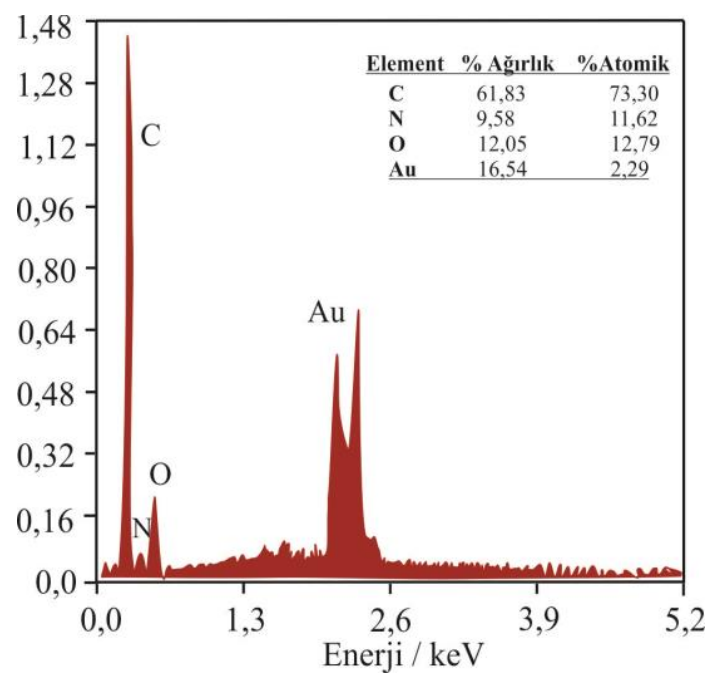

Şekil 2. PAni-Kitosan/Au kompozit filminin EDS analizi

Enerji dağılım spektrumu, PAni-Kitosan kompozit yapisinda var olan atomlardan karbon, azot ve oksijenin yanında, daha sonra elektrodepozisyon ile yüzeye ayrıştırılan altının yapıya katıldığını doğrulamaktadır.
Kitosan zinciri üzerinde bulunan $-\mathrm{NH}_{2}$ ve $-\mathrm{OH}$ grupları ile polianilin zinciri üzerindeki azot atomu arasında oluşan hidrojen bağları sonucunda meydana gelen PAni-Kitosan yapısının şematik gösterimi Şekil 3 'te görülmektedir.

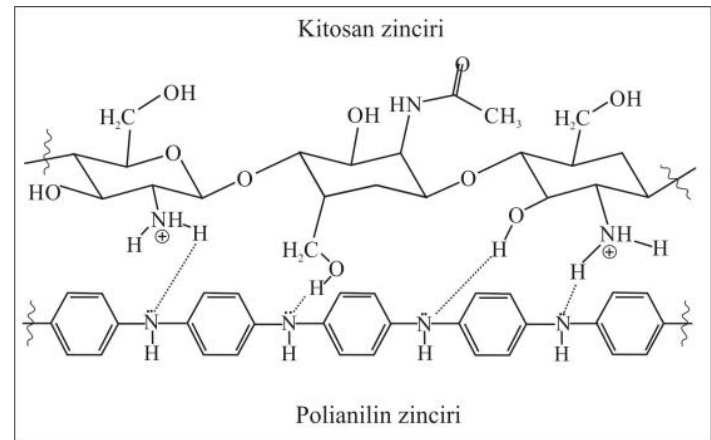

Şekil 3. PAni-Kitosan kompozit filmi

\subsection{Yapı Analizleri}

Alüminyum elektrot üzerine kaplanan PAni, PAniKitosan ve PAni-Kitosan/Au filmlerinin yap analizleri FT-IR spektroskopisiyle incelenmiş, elde edilen sonuçlar Şekil 4'te gösterilmiştir. Yüzeye kaplanan polianilin filminin kitosan ile etkileşimleri ve PAni-Kitosan filminin $\mathrm{Au}$ metaliyle etkileşimleri karşılaştırılmıştır.

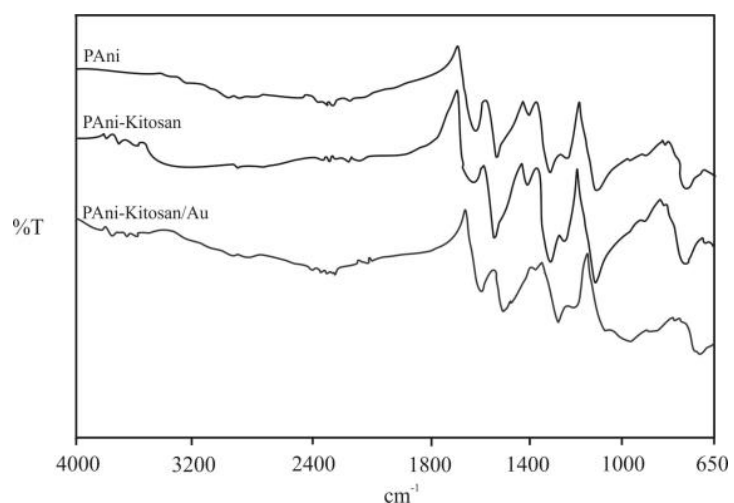

Şekil 4. a) PAni filminin, b) PAni-Kitosan ve c) PAni-Kitosan/Au kompozit filmlerinin FT-IR spektrumları

Polianilinin karakteristik bantları olan, "benzenoid" yapısına ait $\mathrm{C}=\mathrm{C}$ ve $\mathrm{C}=\mathrm{N}$ pikleri 1500 $\mathrm{cm}^{-1}$ ve "quinoid" yapısına ait $\mathrm{C}=\mathrm{C}$ ve $\mathrm{C}=\mathrm{N}$ pikleri 
$1590 \mathrm{~cm}^{-1}$ dolaylarında gözlemlenmiştir. Yapıya kitosan katıldığında, elde edilen spektrumun saf PAni spektrumuna çok benzediği, ancak 2880 ve $3440 \mathrm{~cm}^{-1}$ arasında gözlenen karaktersitik bantların genişlediği görülmüştür. $\mathrm{Bu}$ durumun, PAni ile kitosanın yapısında bulunan $-\mathrm{OH}$ ile $-\mathrm{NH}_{2}$ grupları arasında gerçekleşen hidrojen bağlarından kaynaklandığı bilinmektedir. Ayrıca yapıya altının katılmasıyla, 1597,1512 ve $1335 \mathrm{~cm}^{-1}$, de gözlenen aromatik halkaya ait $\mathrm{C}=\mathrm{C}$ ve $\mathrm{C}=\mathrm{N}$ gerilmelerinin daha düşük dalga sayılarına kaydığı gözlemlenmiştir.

\subsection{Voltametrik Çalışmalar}

Suyun elektroliziyle hidrojen eldesi, katotta meydana gelen,

$2 \mathrm{H}^{+}+2 \mathrm{e}^{-} \rightarrow \mathrm{H}_{2}$

yarı tepkimeye göre gerçekleşir. $\mathrm{Bu}$ yarı tepkimenin potansiyeli,

$\mathrm{E}=\mathrm{E}^{\mathrm{O}}+(\mathrm{RT} / \mathrm{F}) \ln \mathrm{H}_{\mathrm{H}^{+}}-(\mathrm{RT} / 2 \mathrm{~F}) \ln \mathrm{p}_{\mathrm{H} 2}$

eşitliği ile hesaplanır. Hidrojen elektrot için $\mathrm{E}^{\mathrm{o}}=0,0 \mathrm{~V}$ olarak kabul edildiğinden yukarıda eşitlik

$\mathrm{E}=-0,059 \mathrm{pH}-(\mathrm{RT} / 2 \mathrm{~F}) \ln \mathrm{p}_{\mathrm{H} 2}$

olarak ifade edilir. Hidrojen çıkışı gerçekleştiğinde $\mathrm{pH}_{2}=1$ atm olarak kabul edilir ve bu durumda potansiyel $\mathrm{pH}$ ile doğrudan ilişkili olur. Alüminyum elektrot yüzeyine kaplanan PAni-Kitosan kompozit filminin ve bu film üzerine $\mathrm{Au}$ nanopartiküllerin elektrodepozisyonuyla elde edilen kompozit filmin, 0,5 $\mathrm{M} \mathrm{H}_{2} \mathrm{SO}_{4}$ elektrolit ortamında hidrojen gazı oluşumundaki performansları dönüşümlü voltametri tekniğiyle incelenmiştir. $-0,5 \mathrm{~V}$ ile $-1,5 \mathrm{~V}$ potansiyel aralığında, $20 \mathrm{mV} / \mathrm{s}$ tarama hızıyla $0,5 \quad \mathrm{M} \quad \mathrm{H}_{2} \mathrm{SO}_{4}$ elektrolit ortamında kaydedilen voltamogramlar Şekil 5'te görülmektedir. Ayrıca PAni filmine katılan kitosanın etkisini görebilmek amacıyla aynı elektropolimerizasyon şartlarında alüminyum elektrot yüzeyine sadece PAni filmi kaplanarak sulu asidik ortamda hidrojen oluşumuna ait voltamogramlar karşılaştırılmıştır.

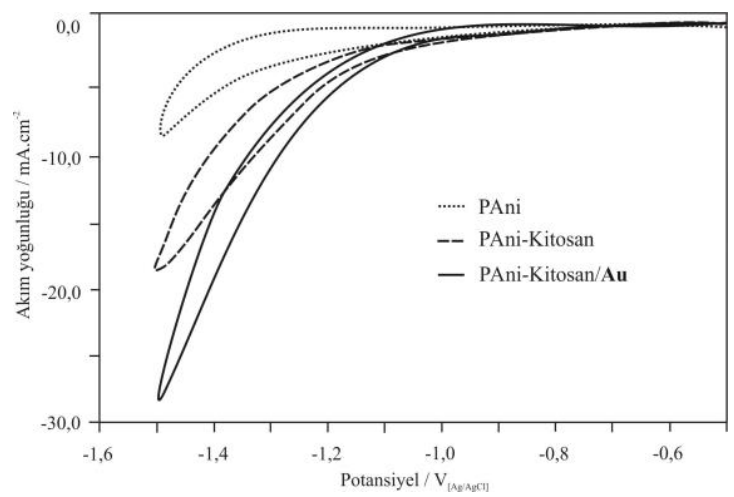

Şekil 5. Alüminyum elektrot üzerine kaplanmış PAni filminin, PAni-Kitosan ve PAniKitosan/Au kompozit filmlerinin 0,5 M $\mathrm{H}_{2} \mathrm{SO}_{4}$ elektrolit ortaminda kaydedilen dönüşümlü voltamogramları $\left(v=20 \mathrm{mV} . \mathrm{s}^{-1}\right)$

Tüm kaplamalarda sulu asidik ortamda, hidrojen oluşumuna ait akım yoğunluğu negatif potansiyellere doğru gidildikçe artmış, ancak PAni ile karşılaştırıldığında, PAni-Kitosankompozit film üzerinde daha yüksek akım yoğunluğuna ulaşıldığı görülmüştür. İletken filmin yapısına hidrojen bağlarıyla katılan kitosanın, filmin gözeneklerine girmesiyle daha iyi bir film oluşturduğu dolayısıyla oluşan daha az pürüzlü filmin daha hızlı elektron transferini sağlayarak elektrik iletkenliğini arttırdığı görülmüştür [23-25]. Kompozit film üzerine $\mathrm{Au}$ nanopartiküllerinin ayrıştırılmasıyla elde edilen PAni-Kitosan/Au kompozit filmi üzerinde ise hidrojen oluşumuna ait akım yoğunluklarının çok daha belirgin bir şekilde arttığ1 görülmüştür. Altın nanopartiküllerin, hidrojen oluşumunda gösterdiği katalitik aktivite, özellikle -1,0 V'tan daha negatif potansiyellere gidildikçe belirgin bir şekilde gözlemlenmiştir.

\subsection{Tafel Polarizasyon Ĕgrileri}

Tafel polarizasyon eğrileri, elektrokimyasal bir proseste, elektrokatalitik aktivitelerin değerlendirilmesinde en çok bilgi veren yöntemlerden birisidir. Alüminyum elektrodun PAni, PAni-Kitosan ve PAni-Kitosan/Au kompozit filmleriyle modifikasyonu sonucunda elde edilen yapılar üzerinde, $0,5 \mathrm{M} \mathrm{H}_{2} \mathrm{SO}_{4}$ elektrolit ortamında $-0,6 \mathrm{~V}$ ile $-1,4 \mathrm{~V}$ potansiyel aralığında kaydedilen Tafel eğrileri Şekil 6'da görülmektedir. 
Polianilin iletken filmi üzerinde, uygulanan potansiyel aralı̆̆ında hidrojen oluşumuna aitakım yoğunluklarının, PAni-Kitosan kompozit filmi üzerinde artış gösterdiği görülmektedir. Kompozit yapıya $\mathrm{Au}$ nanopartiküllerin ayrıştırılmasıyla, aynı potansiyel aralığında elde edilen akım yoğunluğunun belirgin bir şekilde arttığ1 görülmüştür.

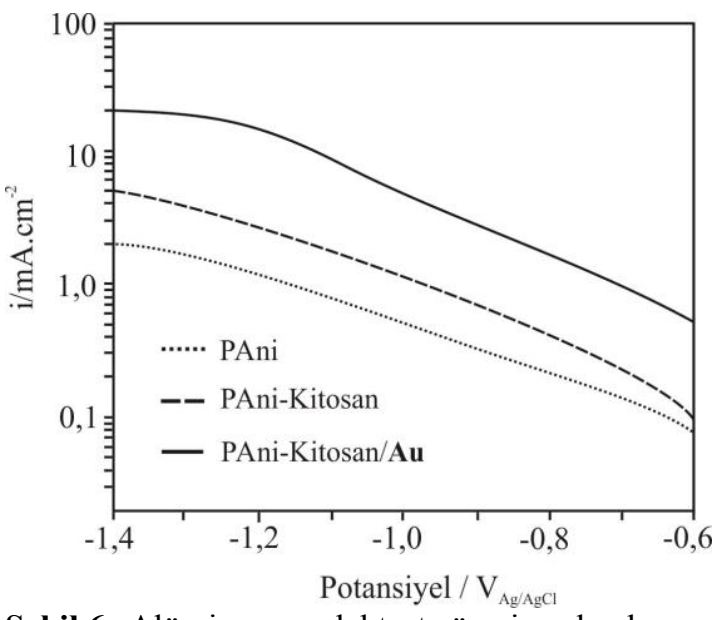

Şekil 6. Alüminyum elektrot üzerine kaplanmıs PAni filminin, PAni-Kitosan ve PAniKitosan/Au kompozit filmlerinin 0,5 M $\mathrm{H}_{2} \mathrm{SO}_{4}$ elektrolit ortamında kaydedilen Tafel polarizasyon eğrileri $\left(v=1 \mathrm{mV} \cdot \mathrm{s}^{-1}\right)$

Elektrot materyallerinin elektrokatalitik aktivitelerinin değerlendirilmesinde Tafel Eşitliğinden yararlanılarak Tafel analizleri yapılmaktadır. Bu analizde, uygulanan potansiyele karşı elde edilen akım değeri olan Tafel eğimi ve değişim akım yoğunluğu değerlerinden tepkimenin kinetiği ile ilgili bilgiler elde edilmektedir. Tafel eğimi, Tafel eğrisinin lineer kısmı olup Eşitlik 4'te verilen Tafel eşitliğinden hesaplanmaktadır;

$\eta=a+b \log i$

Eşitlikte, $\eta$ ile gösterilen uygulanan aşırı gerilim (V), i; akım yoğunluğu $\left(\mathrm{mA} / \mathrm{cm}^{2}\right)$, a; değişim akım yoğunluğu ile ilişkili kayma değeri $\left(\mathrm{mA} / \mathrm{cm}^{2}\right)$ ve $b$; Tafel eğimidir (V/decade). Düşük Tafel eğimi ve yüksek değişim akım yoğunluğuna sahip olan materyallerin, hidrojen oluşumunda daha yüksek katalitik aktivite gösterdikleri bilinmektedir [26].
Ancak son yıllarda değișim akım yoğunluğuna ek olarak, belirli bir potansiyelde elde edilen akım yoğunluğunun ve belirli bir akım yoğunluğuna ulaşmak için uygulanması gereken potansiyel değerlerinin karşılaştırılmasının, katalizörün etkinliği ile ilgili daha somut bilgi verdiği kabul edilmektedir. Belirli bir potansiyelde ne kadar yüksek akım yoğunluğu elde edilir ve belirli bir akım yoğunluğuna ne kadar düşük bir potansiyel değeriyle ulaşılırsa, kullanılan elektrokatalizörün o kadar etkin olduğu söylenebilmektedir.

Kaydedilen Tafel eğrilerinden gerekli hesaplamalar yapılarak belirlenen Tafel eğimleri (b), belirli bir potansiyelde $(\eta=-1,2 \mathrm{~V})$ elde edilen akım yoğunlukları ve belirli bir akım yoğunluğuna $\left(1 \mathrm{~mA} . \mathrm{cm}^{-2}\right)$ ulaşmak için uygulanması gereken potansiyel değerleri Çizelge1'de özetlenmiştir.

Çizelge 1. PAni, PAni-Kitosan ve PAniKitosan/Au kompozit filmleriyle kaplanmıș alüminyum elektrot üzerinde kaydedilen Tafel polarizasyon eğrilerinden hesaplanan elektrokimyasal parametreler

\begin{tabular}{|c|c|c|c|}
\hline Film & $\stackrel{-b}{\text { mVdec }^{-1}}$ & $\begin{array}{c}\mathrm{i} / \mathrm{mA} \mathrm{cm}^{-2} \\
\eta=-1,2 \mathrm{~V}\end{array}$ & $\begin{array}{c}-\eta / V \\
\left.(1 \mathrm{~mA} \mathrm{~cm})^{-2}\right)\end{array}$ \\
\hline PAni & 227 & 1,24 & 1,16 \\
\hline $\begin{array}{l}\text { PAni- } \\
\text { Kitosan }\end{array}$ & 173 & 3,83 & 0,96 \\
\hline $\begin{array}{l}\text { PAni- } \\
\text { Kitosan/Au }\end{array}$ & 148 & 18,12 & 0,70 \\
\hline
\end{tabular}

Çizelge verileri incelendiğinde, PAni filmi üzerinde $227 \mathrm{mV} / \mathrm{dec}$ olarak elde edilen Tafel eğiminin, kitosan varlığında (PAni-Kitosan) 173 $\mathrm{mV} /$ dec'a düştüğü görülmektedir. PAniKitosan/Au kompozit filmi üzerinde $148 \mathrm{mV} / \mathrm{dec}$ olarak hesaplanan daha düşük eğim, $\mathrm{Au}$ nanopartiküllerinin hidrojen oluşumu tepkimesini daha iyi katalizlediğini göstermektedir.

Elektrokimyasal tüm proseslerde en önemli parametre olan birim yüzey alanına düşen akım 
yoğunluğu irdelendiğinde, $1 \mathrm{~mA} / \mathrm{cm}^{2}$ akım yoğunluğuna, PAni filmi üzerinde $-1,16 \mathrm{~V}$ 'ta ulaşıldığı, PAni-Kitosan kompozit yapı üzerinde ise $-0,96 \mathrm{~V}$ gibi daha düşük potansiyel değerinde ulaşıldığ1 görülmüştür. Kompozit filmin $\mathrm{Au}$ nanopartiküller ile modifiye edilmesiyle, bahsedilen akım yoğunluğuna $-0,7 \mathrm{~V}$ 'ta yani daha düşük enerji girdisi ile ulaşıldığı tespit edilmiştir.

\subsection{Elektrokimyasal İmpedans Spektroskopisi}

Elektrokimyasal impedans spektroskopisi, elektrokimyasal proseslerin kinetik incelemeleri ile ilgili oldukça önemli bilgiler vermektedir. Alüminyum elektrot yüzeyinde sentezlenen PAni, PAni-Kitosan ve PAni-Kitosan/Au kompozit filmlerinin hidrojen oluşumundaki elektrokatalitik aktiviteleri elektrokimyasal impedans spektroskopisiyle de incelenmiştir. Nyquist diyagramları olarak değerlendirilen elektrokimyasal impedans spektroskopisi verilerinden, elektrot yüzeyine kaplanan kompozit filmlerin elektron aktarımıyla gerçekleşen hidrojen oluşumundaki performansları karşılaştırılmıştır. $0,5 \mathrm{M} \mathrm{H}_{2} \mathrm{SO}_{4}$ elektrolit ortaminda 0,1 ile 100000 $\mathrm{Hz}$ frekans aralığında $-1,0 \mathrm{~V}$ sabit potansiyelde kaydedilen impedans eğrileri Şekil 7'de gösterilmiştir.

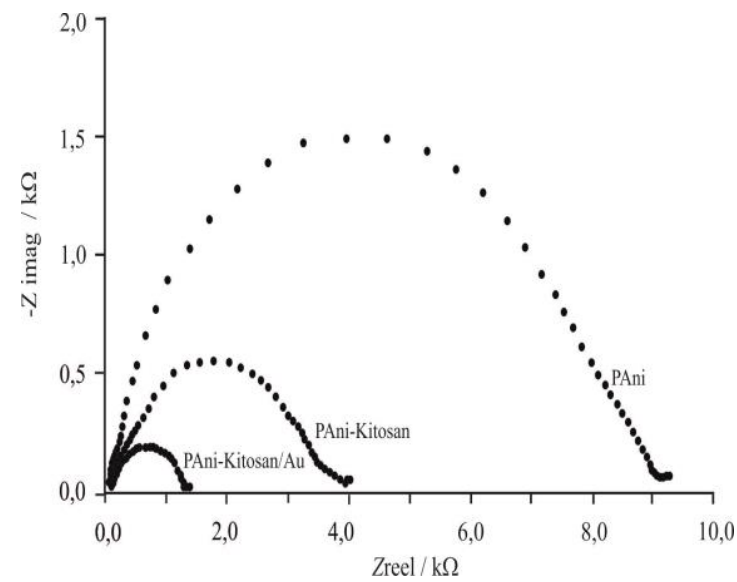

Şekil 7. Alüminyum elektrot üzerine kaplanmış PAni filminin, PAni-Kitosan ve PAniKitosan/Au kompozit filmlerinin 0,5 M $\mathrm{H}_{2} \mathrm{SO}_{4}$ elektrolit ortaminda kaydedilen Nyquist diyagramları
Elektrokatalizörler üzerinde hidrojen oluşumu kinetiği ile ilişkilendirilen yarım dairelerin çaplarının film kompozisyonuna bağlı olarak değiştiği görülmektedir. Çözelti ortamında bulunan $\mathrm{H}^{+}$iyonlarının elektron alarak indirgenmesine karşılık gelen bu yarım dairelerin çapı, yük transfer direnci olarak nitelendirilmiştir. Polianilin filmi için yaklaşık $9 \mathrm{k} \Omega$ olarak hesaplanan yük transfer direncinin, PAni-Kitosan kompozit filmi için yaklaşık $4 \mathrm{k} \Omega$ olarak hesaplandığ1 ve PAniKitosan filmi üzerine $\mathrm{Au}$ nanopartiküllerin ayrıştırılmasıyla elde edilen PAni-Kitosan/Au kompozit filmi üzerinde bu direncin yaklaşık 1,5 $\mathrm{k} \Omega$ ‘a kadar azaldığ 1 tespit edilmiştir. Buradan yola çıkılarak, hidrojen oluşumuna ait elektron transferinin PAni-Kitosan/Au kompozit filmi üzerinde hızlandığı, $\mathrm{Au}$ nanopartiküllerinin tepkimeyi daha iyi katalizlediği sonucuna varılmıştır.

\section{SONUÇLAR}

$\mathrm{Bu}$ çalışmada, alternatif, temiz ve geleceğin enerji kaynağı olarak kabul gören hidrojenin en basit elde edilme yöntemi olan suyun elektroliziyle eldesi için uygun bir elektrokatalizör geliştirilmesi amaçlanmıştır. $\mathrm{Bu}$ amaçla, ucuz bir elektrot materyali olan alüminyum elektrodun yüzeyi, doğal bir biyopolimer olan kitosan varlığında polianilin ile modifiye edilmiş daha sonra bu kompozit yapı üzerine $\mathrm{Au}$ nanopartiküllerin elektrodepozisyonu ile PAni-Kitosan/Au kompozit filmi elde edilmiştir. Elde edilen yapıların yüzey ve yapısal özellikleri karakterize edildikten sonra sentezlenen yapılar üzerinde, sulu asidik ortamda hidrojen oluşumu tepkimesi dönüşümlü voltametri, Tafel polarizasyon eğrileri ve elektrokimyasal impedans spektroskopisi teknikleri kullanılarak incelenmiştir. Kitosanın yapıya katılmasıyla daha iyi bir film elde edildiği tespit edilmiş, buna bağlı olarak hidrojen oluşumuna ait akım yoğunluğunun arttığı dolayısıyla elektron transferine katkıda bulunduğu tespit edilmiştir. Hidrojen oluşumuna ait katalitik aktivitesi yüksek olan altın metalinin kompozit yapı üzerine nano boyutta ayrıştırılmasıyla, hem katalitik aktivitesi yüksek, hem de saf altın veya platin gibi oldukça pahalı malzemelerin elektrot materyali olarak kullanıldığı 
proseslere göre nispeten ekonomik bir elektrokatalizör geliştirilmiştir.

\section{TEŞEKKÜR}

$\mathrm{Bu}$ projeye sağladı̆̆ı maddi desteğinden dolayı Türkiye Bilimsel ve Teknolojik Araştırma Kurumuna (TÜBİTAK, Proje No: KBAG$114 Z 315)$ teşekkür ederiz.

\section{KAYNAKLAR}

1. Fujishima, A., Honda, K., 1972. Electrochemical Photolysis of Water at a Semiconductor Electrode, Nature, 238, 37-38.

2. Devadas, B., Imae, T., 2016. Hydrogen Evolution Reaction Efficiency by Low Loading of Platinum Nanoparticles Protected By Dendrimers on Carbon Materials, Electrochemistry Communications, 72, 135-139.

3. Tuomi, S., Guil-Lopez, R., Kallio, T., 2016. Molybdenum Carbide Nanoparticles as a Catalyst for the Hydrogen Evolution Reaction and the Effect of $\mathrm{pH}$, Journal of Catalysis, 334, 102-109.

4. Lu, Q., Hutchings, G. S., Yu, W., Zhou, Y., Forest, R. V., Tao, R., Rosen, J., Yonemoto, B. T., Cao, Z., Zheng, H., Xiao, J. Q., Jiao, F., Chen, J. G. 2015. Highly Porous Non-Precious Bimetallic Electrocatalysts for Efficient Hydrogen Evolution, Nature Communications, 6(6567), 1-8.

5. Solmaz, R., Salc1, A., Yüksel, H., Doğrubaş, M., Kardaş, G., 2016. Preparation and Characterization of Pd-modified Raney-type NiZn Coatings and Their Application for Alkaline Water Electrolysis, International Journal of Hydrogen Energy, xxx, 1-12, doi:10.1016/j.ijhydene.2016.07.221.

6. Akyüz, D., Keskin, B., Şahintürk, U., Koca, A., 2016. Electrocatalytic Hydrogen Evolution Reaction on Reduced Grapheneoxide Electrode Decorated with Cobaltphthalocyanine, Applied Catalysis B: Environmental 188, 217-226.

7. Baran, E., Yazici, B., 2016. Effect of Different Nano-structured Ag Doped $\mathrm{TiO}_{2}$-NTs Fabricated by Electrodeposition on the
Electrocatalytic Hydrogen Production, International Journal of Hydrogen Energy, 41(4), 2498-2511.

8. Habibi, B., Pournaghi-Azar, M. H., Razmi, H., Abdolmohammad-Zadeh, H., 2008. Electrochemical Preparation of a Novel, Effective and Low Cast Catalytic Surface for Hydrogen Evolution Reaction, International Journal of Hydrogen Energy, 33, 2668-2678.

9. Rao, C. R. K., Trivedi, D. C., 2005. Chemical and Electrochemical Depositions of Platinum Group Metals and their Applications, Coordination Chemistry Reviews, 249, 613631.

10. Winther-Jensen, B., Fraser, K., Ong, C., Forsyth, M., MacFarlane, D. R., 2010. Conducting Polymer Composite Materials for Hydrogen Generation, Advanced Materials, 22, 1727-1730.

11. Yan, R., Jin, B., 2014. Preparation and Electrochemical Performance of Polyaniline/Pt Microelectrodes, Electrochimica Acta, 115, 449- 453.

12. Spătaru, T., Marcu, M., Banu, A., Roman, E., Spătaru, N., 2009. Electrodeposition of Platinum on Polytyramine-Modified Electrodes for Electrocatalytic Applications, Electrochimica Acta, 54, 3316-3319.

13.Zhao, W., Zhou, X., Xue, Z., Wu, B., Liu, X., Lu, X., 2013. Electrodeposition of Platinum Nanoparticles on Polypyrrole Functionalized Graphene, Journal of Material Science, 48, 2566-2573.

14. Del Valle, M. A., Díaz, F. R., Bodini, M. E., Pizarro, T., Córdova, R., Gómez, H., Schrebler, R., 1998. Polythiophene, Polyaniline and Polypyrrole Electrodes Modified by Electrodeposition of Ptand $\mathrm{Pt}+\mathrm{Pb}$ for Formic Acid Electrooxidation, Journal of Applied Electrochemistry, 28, 943-946.

15. Wysocka-Żołopa, M., Grądzka, E., Szymański, K., Winkler, K., 2013. Electrodeposition of Nickel, Cobalt, and Iron on Polypyrrole Films, Thin Solid Films, 548, 44-51.

16. Liu, Z., Zhang, L., Poyraz, S., Zhang, X., 2013. Conducting Polymer-Metal Nanocomposites Synthesis and their Sensory Applications, Current Organic Chemistry, 17, 2256-2267. 
17. Fujii, S., Kodama, M., Matsuzawa, S., Hamasaki, H., Ohtaka, A., Nakamura, Y., 2011. Conducting Polymer-Metal Nanocomposite Coating on Fibers, Advances in Nanocomposite Technology, Hashim, A. China: InTech.15.

18. Mostafa, T. B., Darwish, A. S., 2014. An Approach Toward Construction of Tuned Chitosan/Polyaniline/Metal Hybrid Nanocomposites for Treatment of Meat Industry Wastewater, Chemical Engineering Journal, 243, 326-339.

19. Adlim, M., Bakar, M. A., Liew, K. Y., Ismail, J., 2004. Synthesis of Chitosan-Stabilized Platinum and Palladium Nanoparticles and their Hydrogenation Activity, Journal of Molecular Catalysis A: Chemical, 212, 141-149.

20. Luo, X. L., Xu, J. J., Zhang, Q., Yang, G. J., Chen, H. Y., 2005. Electrochemically Deposited Chitosan Hydrogel for Horseradish Peroxidase Immobilization Through Gold Nanoparticles Self-Assembly, Biosensors and Bioelectronics, 21, 190-196.

21. Parmuzina, A. V., Kravchenko, O. V., 2008. Activation of Aluminium Metal to Evolve Hydrogen From Water,International Journal of Hydrogen Energy, 33, 3073-3076.

22. Wang, H. Z., Leung, D. Y. C., Leung, M. K. H., Ni, M., 2009. A Review on Hydrogen Production using Aluminum and Aluminum Alloys, Renewable and Sustainable Energy Reviews, 13, 845-853.

23. Silva, R. C., Sarmento, M. V., Nogueira, A. R. F, Tonholo, J., Mortimer, R. J., Faez, R., Ribeiro, A. S., 2014. Enhancing the Electrochromic Response of Polyaniline Films by the Preparation of Hybrid Materials Based on Polyaniline, Chitosan and Organically Modified Clay, RSC Advances, 4, 14948-14955.

24. Varghese, J. G., Kittur, A. A., Rachipudi, P. S., Kariduraganavar, M. Y., 2010. Synthesis, Characterization and Pervaporation Performance of Chitosan-G-Polyaniline Membranes for The Dehydration of Isopropanol, Journal of Membran Science, 364, 111-121.
25. Gök, A., Omastova, M., Yavuz, A. G., 2007. Synthesis and Characterization of Polythiophenes Prepared in the Presence of Surfactants, Synthetic Metals, 157, 23-29.

26. Alhajri, N. S., Yoshida, H., Anjum, D. H., Garcia-Esparza, A. T., Kubota, J., Domen, K., Takanabe, K., 2013. Synthesis of Tantalum Carbide and Nitride Nanoparticles using a Reactive Mesoporous Template for Electrochemical Hydrogen Evolution, Journal of Materials Chemistry A, 1, 12606-12616. 
